UDC 004.942:519.6

$10.23947 / 2587-8999-2017-2-156-163$

\title{
Study of the optimal solution sensitivity of variational data assimilation problem for a model of sea thermodynamics*
}

\author{
V.P. Shutyaev, E.I. Parmuzin** \\ Institute of Numerical Mathematics, Russian Academy of Sciences, Moscow, Russian Federation
}

Algorithms are proposed to study the sensitivity of the optimal solution to the errors of the observational data in the problem of variational assimilation of the sea surface temperature data with the aim of restoring heat fluxes for the nonstationary system of thermodynamic equations. Numerical experiments are presented in an application to the model of the thermodynamics of the Baltic Sea.

Keywords: mathematical modeling; variational data assimilation; optimal control; adjoint equations; sensitivity to errors

Introduction. In the mathematical modeling of climate change for various regions of the world, the sensitivity theory of selected functionals plays an important role in relation to the characteristics of continents, the World Ocean, initial data, external sources and internal parameters of the problem. The study of climate sensitivity makes it possible to evaluate the quality of models on the basis of real data and find new mechanisms responsible for climate formation.

At present, in connection with the research of global changes on the planet Earth, the problem of obtaining and rational use of measurement data for the purpose of retrospective analysis in various fields of knowledge is very important. The mathematical model of this problem can be formulated as a problem of assimilation and processing of multidimensional (including dependence on time and space variables) data, which is one of the problems of optimal control ([1]-[5]). Along with the development and justification of algorithms for numerical solution of problems of variational assimilation of observational data, the properties of the optimal solution play an important role ([6][9]). The question of the sensitivity of optimal solutions of variational assimilation problems to the errors of observational data and model parameters, which has not been studied until recently, is extremely important.

In this paper we consider the problem of studying the sensitivity of the optimal solution of the problem of variational assimilation of observational data on the sea surface temperature for the thermodynamic model in a formulation analogous to that introduced in [5]. On the basis of the relationships connecting the errors of the optimal solution of the problem of variational assimilation with the errors of the observational data through the Hessian of the cost functional, algorithms for calculating the sensitivity coefficients as the norms of the response operators arising in the equations for the errors are proposed.

\footnotetext{
* The research is done with the financial support from RSF Project No. 14-11-00609, studies in sections 2-3, and RFBR Project No. 15-01-01583, within which numerical calculations were performed.

**E-mail: parm@inm.ras.ru, shutyaev@inm.ras.ru.
} 
1. The problem of assimilation of observational data for the thermodynamics of the sea. Let us consider the model of the thermodynamics of the sea in the form ([10], [11]):

$$
\begin{gathered}
T_{t}+(\bar{U}, G r a d) T-\operatorname{Div}\left(\hat{a}_{T} \cdot \operatorname{Grad} T\right)=f_{T} \text { in } D \times\left(t_{0}, t_{1}\right), \\
T=T_{0} \text { at } t=t_{0} \text { in } D, \\
-v_{T} \frac{\partial T}{\partial z}=Q \text { on } \Gamma_{S} \times\left(t_{0}, t_{1}\right), \quad \frac{\partial T}{\partial N_{T}}=0 \text { on } \Gamma_{w, c} \times\left(t_{0}, t_{1}\right), \\
\bar{U}_{n}^{(-)} T+\frac{\partial T}{\partial N_{T}}=\bar{U}_{n}^{(-)} d_{T}+Q_{T} \text { on } \Gamma_{w, o p} \times\left(t_{0}, t_{1}\right), \\
\frac{\partial T}{\partial N_{T}}=0 \text { on } \Gamma_{H} \times\left(t_{0}, t_{1}\right),
\end{gathered}
$$

where $T=T(x, y, z, t)$ - the unknown temperature function, $t \in\left(t_{0}, t_{1}\right),(x, y, z) \in D=\Omega \times(0, H)$, $\Omega \subset R^{2}, H=H(x, y)$ - the bottom relief function, $Q=Q(x, y, t)$ - the heat flow through the upper boundary, $\bar{U}=(u, v, w), \quad a_{T}=\operatorname{diag}\left(\left(a_{T}\right)_{i i}\right), \quad\left(a_{T}\right)_{11}=\left(a_{T}\right)_{22}=\mu_{T}, \quad\left(a_{T}\right)_{33}=v_{T}, f_{T}=f_{T}(x, y, z, t)-$ given functions. The boundary of the region $\Gamma \equiv \partial D$ is represented as the union of four disjoint parts $\Gamma_{S}, \Gamma_{w, o p}, \Gamma_{w, c}, \Gamma_{H}$, where $\Gamma_{S}=\Omega$ (unperturbed sea surface), $\Gamma_{w, o p}-$ the liquid (open) part of the vertical lateral boundary, $\Gamma_{w, c}$ - the solid part of the vertical lateral boundary, $\Gamma_{H}-$ the bottom of the sea. Other notations and a detailed description of the statement of the problem can be found in [5], [10].

The problem (1.1) can be written in the form of an operator equation:

$$
\begin{aligned}
T_{t}+L T & =F+B Q, \quad t \in\left(t_{0}, t_{1}\right), \\
T & =T_{0} \text { at } t=t_{0},
\end{aligned}
$$

where equality is understood in the weak sense, namely:

$$
\left(T_{t}, T\right)+(L T, T)=F(T)+(B Q, T) \quad \forall T \in W_{2}^{1}(D),
$$

in this case $L, F, B$ are determined by the following relations:

$$
\begin{gathered}
(L T, T) \equiv \int_{D}(-T D i v(\bar{U} T)) d D+\int_{\Gamma_{w, o p}} \bar{U}_{n}^{(+)} T T d \Gamma+\int_{D} a_{T} \operatorname{Grad}(T) \cdot \operatorname{Grad}(T) d D, \\
F(T)=\int_{\Gamma_{w, o p}}\left(Q_{T}+\bar{U}_{n}^{(-)} d_{T}\right) T d T+\int_{D} f_{T} T d D \\
\left(T_{t}, T\right)=\int_{D} T_{t} T d D,(B Q, T)=\left.\int_{\Omega} Q T\right|_{z=0} d \Omega
\end{gathered}
$$

and the functions $a_{T}, Q_{T}, f_{T}, Q$ are such that equality (1.3) makes sense. The properties of the operator $L$ were investigated in [5].

We shall consider the problem of assimilating data on the temperature of the sea surface (see [5]). Suppose that the function $Q \in L_{2}\left(\Omega \times\left(t_{0}, t_{1}\right)\right)$ is unknown in (1.1). Suppose that we have given a function of the observational data $T_{\mathrm{obs}}(x, y, t)$ on $\bar{\Omega} \equiv \Omega \cup \partial \Omega$ at $t \in\left(t_{0}, t_{1}\right)$, which, in its physical meaning, is an approximation to the surface temperature function on $\Omega$, i.e. to $\left.T\right|_{z=0}$. We assume 
that $T_{\text {obs }} \in L_{2}\left(\Omega \times\left(t_{0}, t_{1}\right)\right)$, however, the function $T_{\text {obs }}$ may not be more smooth, so it can not be used as the boundary condition on $\Gamma_{S}$. A case is possible when $T_{\text {obs }}$ there is given only on a subset of $\Omega \times\left(t_{0}, t_{1}\right)$, whose characteristic function is denoted by $m_{0}$. Outside this subset, for definiteness, $T_{\mathrm{obs}}$ is considered to be trivial.

Consider the following data assimilation problem: find $T$ and $Q$ such that

$$
\left\{\begin{array}{ccc}
T_{t}+L T & = & F+B Q, \text { in } D \times\left(t_{0}, t_{1}\right), \\
T & = & T_{0} \text { at } t=t_{0} \\
J(Q) & = & \inf _{Q} J(Q),
\end{array}\right.
$$

where $J(Q)=\frac{\alpha}{2} \int_{t_{0}}^{t_{1}} \int_{\Omega}\left|Q-Q^{(0)}\right|^{2} d \Omega d t+\frac{1}{2} \int_{t_{0}}^{t_{1}} \int_{\Omega} m_{0}|T|_{z=0}-\left.T_{o b s}\right|^{2} d \Omega d t$,

$Q^{(0)}=Q^{(0)}(x, y, t)$ - specified function, $\alpha=$ const $>0$. The functiona $J$ determines the root-meansquare deviation from the observed values.

With $\alpha>0$ the problem of variational data assimilation has a unique solution. The existence of an optimal solution follows from the classical results of the theory of extremal problems, since it is not difficult to show that the solution of problem (1.2) depends continuously on the flow $Q$ (a priori estimates hold in the corresponding function spaces). With $\alpha=0$ the problem does not always have a solution, however, as shown in [5], there is a unique and dense solvability, which allows us to construct a sequence of regularized solutions that minimizes the functional.

The optimality system, which determines the solution of the problem of variational data assimilation (1.4)-(1.5) according to the necessary condition, has the form:

$$
\begin{gathered}
T_{t}+L T=F+B Q \quad \text { in } D \times\left(t_{0}, t_{1}\right), \\
T=T_{0} \text { at } t=t_{0}, \\
-\left(T^{*}\right)_{t}+L^{*} T^{*}=B m_{0}\left(T-T_{\mathrm{obs}}\right) \text { in } D \times\left(t_{0}, t_{1}\right), \\
T^{*}=0 \text { at } t=t_{1}, \\
\alpha\left(Q-Q^{(0)}\right)+T^{*}=0 \quad \text { on } \Omega \times\left(t_{0}, t_{1}\right),
\end{gathered}
$$

where $L^{*}$ - the operator adjoint to $L$.

In what follows we assume that $\operatorname{supp}\left(m_{0}\right)=\bar{\Omega} \times\left[t_{0}, t_{1}\right]$ and we will investigate the sensitivity of the optimal solution $Q$ to the input data, namely, to the errors in the specification of the functions $T_{o b s}$ and $Q^{(0)}$.

As a result of solving the problem of variational assimilation of the data (1.6)-(1.8), we obtain the total flow function $Q$, which is the optimal solution in the sense of minimizing the functional (1.5). This solution depends on the function of the observational data $T_{\text {obs }}$ on the sea surface. An important question is the sensitivity of the optimal solution to the changes in the function $T_{\text {obs }}$. This issue is of great importance from the point of view of the forecast, since the optimal solution found as a result of solving the variational assimilation problem is used to integrate the model in the next 
time interval. In this section, algorithms for studying the sensitivity of the optimal solution to the errors of the observational data are considered.

Let the observation data be given with errors:

$$
Q^{(0)}=\bar{Q}+\xi_{1}, T_{\text {obs }}=\left.\bar{T}\right|_{z=0}+\xi_{2},
$$

where $\bar{T} \in L_{2}\left(\Omega \times\left(t_{0}, t_{1}\right)\right), \bar{T}$ is the exact solution of the direct problem for: $Q=\bar{Q}$ :

$$
\begin{gathered}
\bar{T}_{t}+L \bar{T}=F+B \bar{Q} \quad \text { in } D \times\left(t_{0}, t_{1}\right), \\
\bar{T}=T_{0} \quad \text { at } t=t_{0} .
\end{gathered}
$$

The functions $\xi_{1}, \xi_{2}$ can be considered as errors in the input data $Q^{(0)}$ and $T_{\text {obs }}$ accordingly. The influence of these errors on the optimal solution $Q$ obtained from the optimality system (1.6)(1.8) was investigated in $[6,12]$, where it was shown that the equation for the error of the optimal solution at $\alpha>0$ has a unique solution

$$
\delta Q=\alpha H^{-1} \xi_{1}+H^{-1} R \xi_{2},
$$

where $H=H_{0}+\alpha E, E$ - the identity operator, $H_{0}$ is determined on $v \in L_{2}\left(\Omega \times\left(t_{0}, t_{1}\right)\right)$ by sequential solution of the problems:

$$
\begin{gathered}
\psi_{t}+L \psi=B v \quad \text { in } D \times\left(t_{0}, t_{1}\right), \\
\psi=0 \quad \text { at } t=t_{0}, \\
-\left(\psi^{*}\right)_{t}+L^{*} \psi^{*}=B m_{0} \psi \quad \text { in } D \times\left(t_{0}, t_{1}\right), \\
\psi^{*}=0 \quad \text { at } t=t_{1}, \\
H_{0} v=\psi^{*} \quad \text { on } \Omega \times\left(t_{0}, t_{1}\right),
\end{gathered}
$$

and the operator $R$ acts on functions $g \in L_{2}\left(\Omega \times\left(t_{0}, t_{1}\right)\right)$ by the formula $R g=\left.\theta^{*}\right|_{z=0}$, where $\theta^{*}-$ is the solution of the adjoint problem

$$
\begin{gathered}
-\left(\theta^{*}\right)_{t}+L^{*} \theta^{*}=B m_{0} g \text { in } D \times\left(t_{0}, t_{1}\right), \\
\theta^{*}=0 \text { at } t=t_{1} .
\end{gathered}
$$

We note that the operator $H$ is the Hessian of the functional $J$ defined by (1.5).

Thus, the error of the optimal solution $\delta Q$ is explicitly expressed in terms of the errors of the initial data $\xi_{1}, \xi_{2}$. In [12] the properties of the operators of the problem are studied in detail and estimates for the sensitivity coefficients describing the sensitivity of the optimal solution of the problem of variational assimilation of observational data for the sea dynamics model are presented. As a characteristic of the sensitivity of the optimal solution to the errors of the observational data, we consider the value

$$
r=\sqrt{\square H_{0}\left(H_{0}+\alpha E\right)^{-2} \square}
$$

where $H_{0}$ is given by formulas (1.12)-(1.14). The coefficient $r$ characterizes the magnitude of the norm of the response operator $H^{-1} R$ in equation (1.11). We note that the upper bound for the spectrum of the operator $H_{0}\left(H_{0}+\alpha E\right)^{-2}$ can be considered as the norm in (1.15). For finitedimensional approximation, the operator $H_{0}$ is a matrix and the coefficient $r$ is calculated by the formula: 


$$
r=\sup _{k} \frac{\sqrt{\mu_{k}}}{\alpha+\mu_{k}}
$$

where $\mu_{k}$ - the eigenvalues of $H_{0}$, and $\frac{\sqrt{\mu_{k}}}{\alpha+\mu_{k}}$ - the singular numbers of the operator $H^{-1} R$.

On the basis of the above, we can formulate the following algorithm for calculating the sensitivity coefficient of the optimal solution to the errors of the observational data:

1) calculate the Hessian $H_{0}$, determined by the formulas (1.12)-(1.14);

2) find the eigenvalues of the Hessian $H_{0}$;

3) calculate the sensitivity coefficient $r$ by formula (1.16).

Here it should be emphasized that for finite-dimensional approximation $H_{0}$ turns out to be a poorly conditioned matrix, for which the smallest eigenvalue $\mu_{\min }$ is close to zero. In this case, when $\alpha=0$ the coefficient $r=\frac{1}{\sqrt{\mu_{\min }}}$ can be sufficiently large, i.e. the optimal solution can be very sensitive to observation errors. This means that in this case it is necessary to introduce a regularizer with a parameter $\alpha>0$, which will make the task of determining the optimal solution stable with respect to errors of observations.

2.Results of numerical experiments. For numerical experiments, we used the threedimensional numerical model of the hydrothermodynamics of the Baltic Sea, developed in the INM of the Russian Academy of Sciences on the basis of the splitting method [13] and supplemented with the assimilation procedure [5] of the surface temperature with the aim of restoring heat fluxes. We present some results of numerical experiments on the sensitivity of the optimal solution.

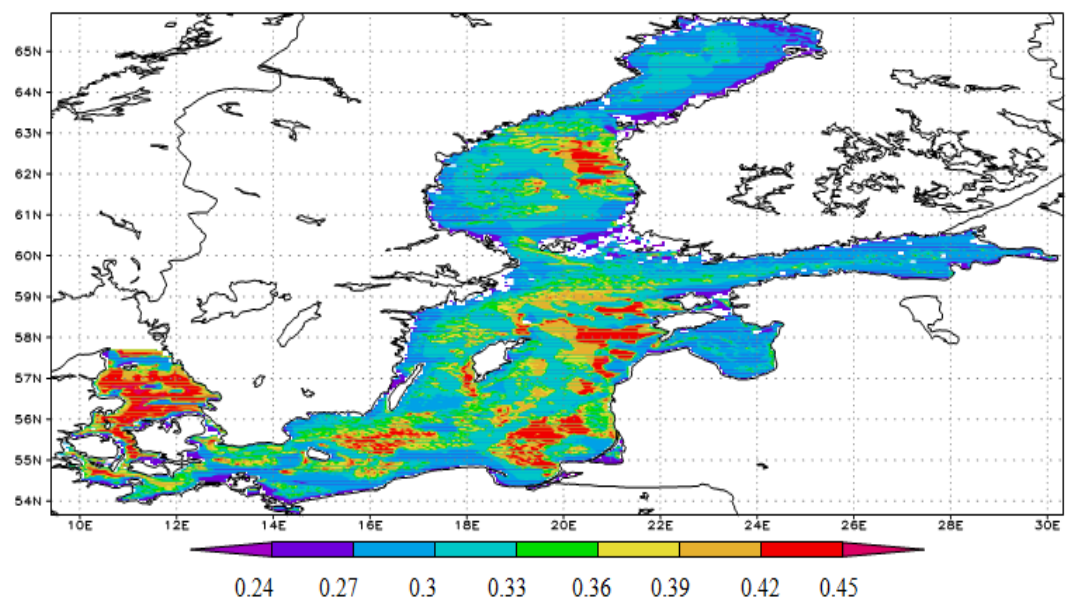

Fig. 1. Singular numbers of the operator after 1000 calculation steps

Fig. 1 shows the singular numbers of the operator $H^{-1} R$, which determine the sensitivity coefficient $r$. The largest singular numbers correspond to points lying near the regions with a small depth, especially in places on the slopes of the depressions. Thus, the optimal solution proves to be 
sensitive to the errors of observations at the points of the surface near these regions, and the stability of the problem of restoring heat fluxes on the surface can degrade at these points.

Conclusion. In this paper, numerical algorithms for studying the sensitivity of the solution of the problem of variational assimilation of data on the temperature of the sea surface with the aim of restoring heat fluxes on the surface are considered. The equation for the error of the optimal solution through errors in the observational data is related to the Hessian of the original observation functional. This equation leads to the determination of the sensitivity coefficients as norms of response operators that characterize the degree of influence of errors in the observational data on the optimal solution of the problem of variational assimilation. The proposed methodology makes it possible to determine the subregions in which the optimal solution is most sensitive to observation errors in the variational assimilation of data, image processing, in the case where the values of the errors are not known in advance.

\section{References}

1. Marchuk G.I. Adjoint Equations and Analysis of Complex Systems. - Dordrecht: Kluwer, 1995. - $466 \mathrm{p}$.

2. Marchuk G. I., Penenko V.V. Application of optimization methods to the problem of mathematical modeling of the atmospheric processes and environment // In: Modeling and Optimization of Complex Systems: Proc. of the IFIP-TC7 Working conf. - New York: Springer, 1978, pp. 240-252.

3. Le Dimet F.X., Talagrand O. Variational algorithms for analysis and assimilation of meteorological observations: theoretical aspects // Tellus. - 1986. - V.38A. - pp. 97-110.

4. Shutyaev V.P. Operators of control and iterative algorithms in problems of variational data assimilation. - Moscow: Nauka, 2001. - 239 p.

5. Agoshkov V.I., Parmuzin E.I., Shutyaev V.P. Numerical algorithm for variational assimilation of observational data on the temperature of the ocean surface // ZhVM and MF. - 2008 . - T.48, №8. - pp.1371-1391.

6. Le Dimet F.-X., Shutyaev V. On deterministic error analysis in variational data assimilation // Nonlinear Processes in Geophysics. - 2005. - V.12. - pp.481-490.

7. Gejadze I., Le Dimet F.-X., Shutyaev V.P. On analysis error covariances in variational data assimilation // SIAM J. Sci. Comput. - 2008. - V.30, no.4. - pp.1847-1874.

8. Gejadze I., Le Dimet F.-X., Shutyaev V.P. On optimal solution error covariances in variational data assimilation problems // J. Comp. Phys. - 2010. - V.229. - pp.2159-2178.

9. Gejadze I., Shutyaev V.P., Le Dimet F.-X. Analysis error covariance versus posterior covariance in variational data assimilation // Quartely Journal of the Royal Meterological Society. 2013. - V.139. - pp.1826-1841.

10. Alekseev V.V., Zalesny V.B. Numerical model of large-scale ocean dynamics // Computational processes and systems. - Moscow: Nauka, 1993, pp. 232-253.

11. Marchuk G.I., Dymnikov V.P., Zalesny V.B. Mathematical models in geophysical hydrodynamics and numerical methods for their implementation. - L .: Gidrometeoizdat, 1987. - 352 p. 
12. Parmuzin E.I., Shutyaev V.P. The study of solution sensitivity for the variational observation data assimilation problem in the Black Sea dynamics model. J. Numer. Anal. Math. Modeling. - 2013. - V.28, no.1. - pp. 37-52.

13. Zalesny V.B., Gusev A.V., Chernobay S.Yu., Aps R., Tamsalu R., Kujala P., Rytkönen J. The Baltic Sea circulation modeling and assessment of marine pollution // Russ. J. Numer. Anal. Math. Modeling. - 2014. - V.29, no.2. - pp. 129-138.

\section{Authors:}

Shutyaev Victor Petrovich, Doctor of Science in Physics and Maths, Professor, Scientific Secretary and Leading Researcher of the Institute of Numerical Mathematics of the Russian Academy of Sciences (8 Gubkin St., Moscow, Russian Federation)

Parmuzin Evgeny Ivanovich, Candidate of Science in Physics and Maths, Senior Researcher of the Institute of Numerical Mathematics of the Russian Academy of Sciences (8 Gubkin St., Moscow, Russian Federation) 
УДК 004.942:519.6

\section{Исследование чувствительности оптимального решения задачи вариационного} усвоения данных для модели термодинамики моря *

\section{В.П. Шутяев, Е.И. Пармузин ${ }^{* *}$}

Институт вычислительной математики РАН, Москва, Российская Федерация

Предложены алгоритмы исследования чувствительности оптимального решения к погрешностям данных наблюдений в задаче вариационного усвоения данных о температуре поверхности моря с целью восстановления потоков тепла для нестационарной системы уравнений термодинамики. Представлены численные эксперименты в приложении к модели термодинамики Балтийского моря.

Ключевые слова: математическое моделирование; вариационное усвоение данных; оптимальное управление; сопряженные уравнения; чувствительность к погрешностям

\section{Авторы:}

Шутяев Виктор Петрович, доктор физико-математических наук, профессор, ученый секретарь и ведущий научный сотрудник ИВМ РАН (РФ, 119333, г. Москва, ул. Губкина, 8)

Пармузин Евгений Иванович, кандидат физико-математических наук, старший научный сотрудник ИВМ РАН (РФ, 119333, г. Москва, ул. Губкина, 8)

\footnotetext{
* Работа выполнена при поддержке Российского научного фонда (проект 14-11-00609, исследования в разделах 2-3) и РФФИ (проект 15-01-01583, в рамках которого были проведены численные расчеты)

** E-mail: parm@inm.ras.ru, shutyaev@inm.ras.ru.
} 